\title{
RANCANG BANGUN SISTEM INFORMASI TERPADU FMIPA UNIVERSITAS TADULAKO
}

\author{
M. S. Ismail1 ${ }^{1}$ I W. Sudarsana² dan R. Ratianingsih ${ }^{3}$ \\ 1,2,3 Program Studi Matematika Jurusan Matematika FMIPA Universitas Tadulako \\ Jalan Soekarno-Hatta Km. 09 Tondo, Palu 94118, Indonesia. \\ 1sabrikraton@gmail.com, 2sudarsanaiwayan@yahoo.co.id, 3ratianingsih@yahoo.com
}

\begin{abstract}
The information system is the basis of providing information to users. Efficient information systems that can support the establishment of an effective system and prime serviced. It is difficult to obtain excellent service if a system is running ineffective moreover still classified manually. State University of Tadulako which is an organization of the academic community, should have excellent service in the field of work. Integrated Information System for the Faculty of Mathematics and Natural Sciences Tadulako Univesity is not available, so students do not obtain academic information prima internet-based media. Moreover, the existence of academic policy in each year, resulting in each institution's academic policies changed, which includes courses, assessment, and curriculum. Integrated information system was built using the programming language PHP and MySQL. The findings of this result is the online of academc information system that can be fully accessed by the academic community of Mathemathics and Natural Science Faculity, Tadulako University.
\end{abstract}

\section{Keywords : Academic, Excellent Service, Information System}

\section{ABSTRAK}

Sistem Informasi merupakan basis dalam menyediakan informasi pada para penggunanya. Sistem informasi yang berdaya guna dapat menunjang terwujudnya sebuah sistem secara efektif dan berlayanan prima. Sulit untuk memperoleh layanan prima jika sebuah sistem berjalan tidak efektif terlebih lagi masih tergolong manual. FMIPA Universitas Tadulako yang merupakan wadah para civitas akademik, sebaiknya memilik layanan prima dalam bidang kerjanya. Sistem Informasi Terpadu untuk FMIPA Universitas Tadulako belum tersedia, sehingga mahasiswa belum mendapatkan informasi akademik berbasis media internet secara prima. Terlebih lagi adanya kebijakan akademik ditiap tahunnya mengakibatkan kebijakan akademik disetiap institusi berubah, yang mencakup matakuliah, penilaian, dan kurikulum. Sistem informasi terpadu ini dibangun menggunakan bahasa pemrograman PHP dan MySQL. Hasil yang diperoleh dari penelitian ini adalah rancangan sistem informasi terpadu FMIPA Universitas sebagai pusat informasi akademik secara online yang dapat diakses oleh civitas akademik FMIPA Universitas Tadulako.

Kata Kunci $\quad$ : Akademik, Layanan Prima, Sistem Informasi 


\section{PENDAHULUAN}

Fakultas Matematika IImu Pengetahuan Alam (FMIPA) Universitas Tadulako merupakan tempat dimana para saintis muda berkumpul dan berinteraksi untuk mengembangkan ilmu pengetahuan alam dan juga teknologi. Oleh karena itu bidang akademik harus dikelola dengan baik. Pengelolaan bidang akademik menjadi permasalahan yang sangat kompleks apabila hanya ditangani secara manual. Pengelolaan akademik akan menjadi lebih efektif dan efisien jika menggunakan komputer sebagai alat bantu.

FMIPA belum mempunyai Sistem Informasi Akademik tersendiri. Dalam pelaksanaannya masih bergabung dengan Sistem Informasi Akademik Universitas. Kondisi ini bahkan berimplikasi terhadap tidak maksimalnya pencapaian target akreditasi BAN PT, baik AIPT maupun akreditasi program studi. Hal yang tidak kalah pentingnya adalah hubungan antara Universitas dengan dosen dan mahasiswa, dimana selama ini dosen dan mahasiswa jika ingin mendapatkan informasi harus dengan bertanya langsung kepada unit terkait. Ketidaktersediaan informasi juga sering kali menjadi masalah, mengingat akurasi data merupakan hal yang sangat penting.

Sistem Informasi Terpadu FMIPA Universitas Tadulako ini dirancang dengan menggunakan bahasa pemrograman PHP dan MySql, dimana Sistem Informasi Terpadu ini akan menjadi pusat informasi akademik secara online yang dapat diakses oleh civitas akademika FMIPA Universitas Tadulako utamanya bagi mahasiswa dan dosen.

\section{METODE PENELITIAN}

Penelitian ini dilakukan sesuai prosedur sebagai berikut:

1. Merumuskan masalah

2. Mengumpulkan data.

3. Merancang sistem.

4. Mendesain sistem.

5. Pengujian sistem informasi terpadu FMIPA.

6. Menyimpulkan hasil penelitian. 
Alur penyelesaian penelitian ini mengikuti flowchart berikut.

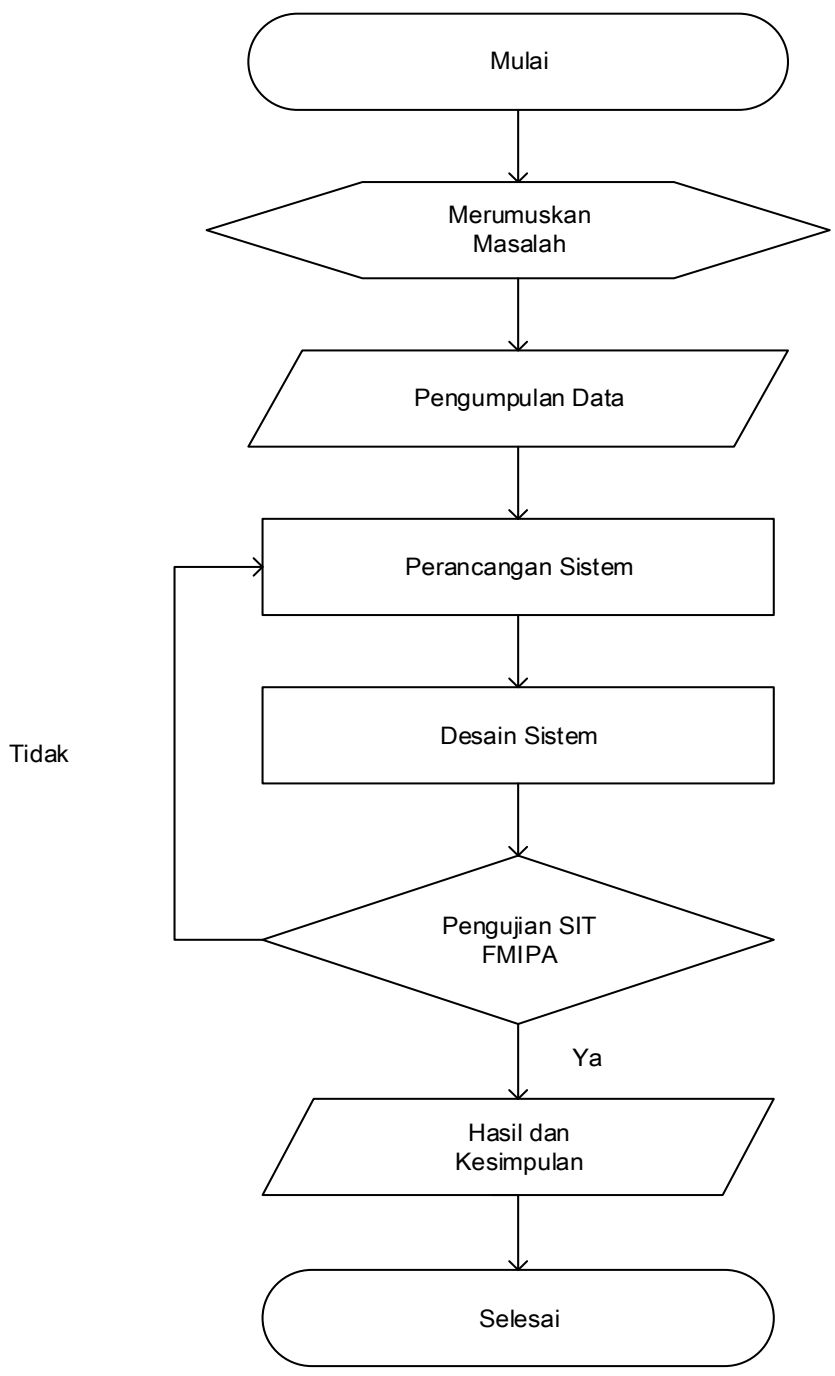

Gambar 1. : Flowchart kerangka pikir Sistem Informasi Terpadu FMIPA Universitas Tadulako 


\section{HASIL DAN PEMBAHASAN}

\subsection{Rancangan Proses}

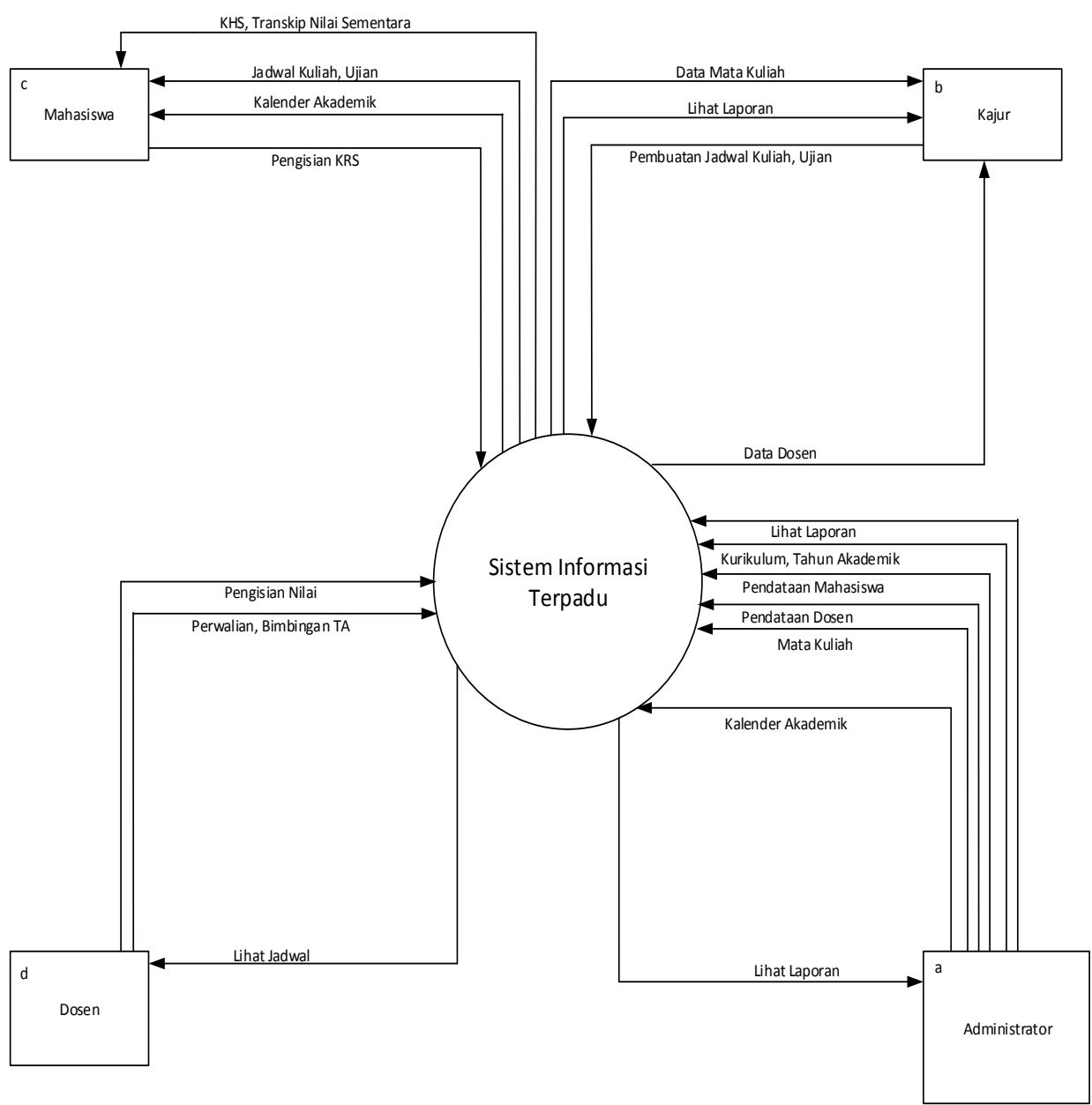

Gambar 2 : Diagram Konteks Sistem Informasi Terpadu FMIPA

Dalam Diagram konteks rancangan proses sistem informasi terpadu FMIPA Universitas Tadulako ini mempunyai 4 (empat) kesatuan luar (external entity) yaitu administrator, ketua jurusan (kajur), dosen, dan mahasiswa. Serta mempunyai 12 (dua belas) proses yang selanjutnya akan dijabarkan pada diagram level 1. 


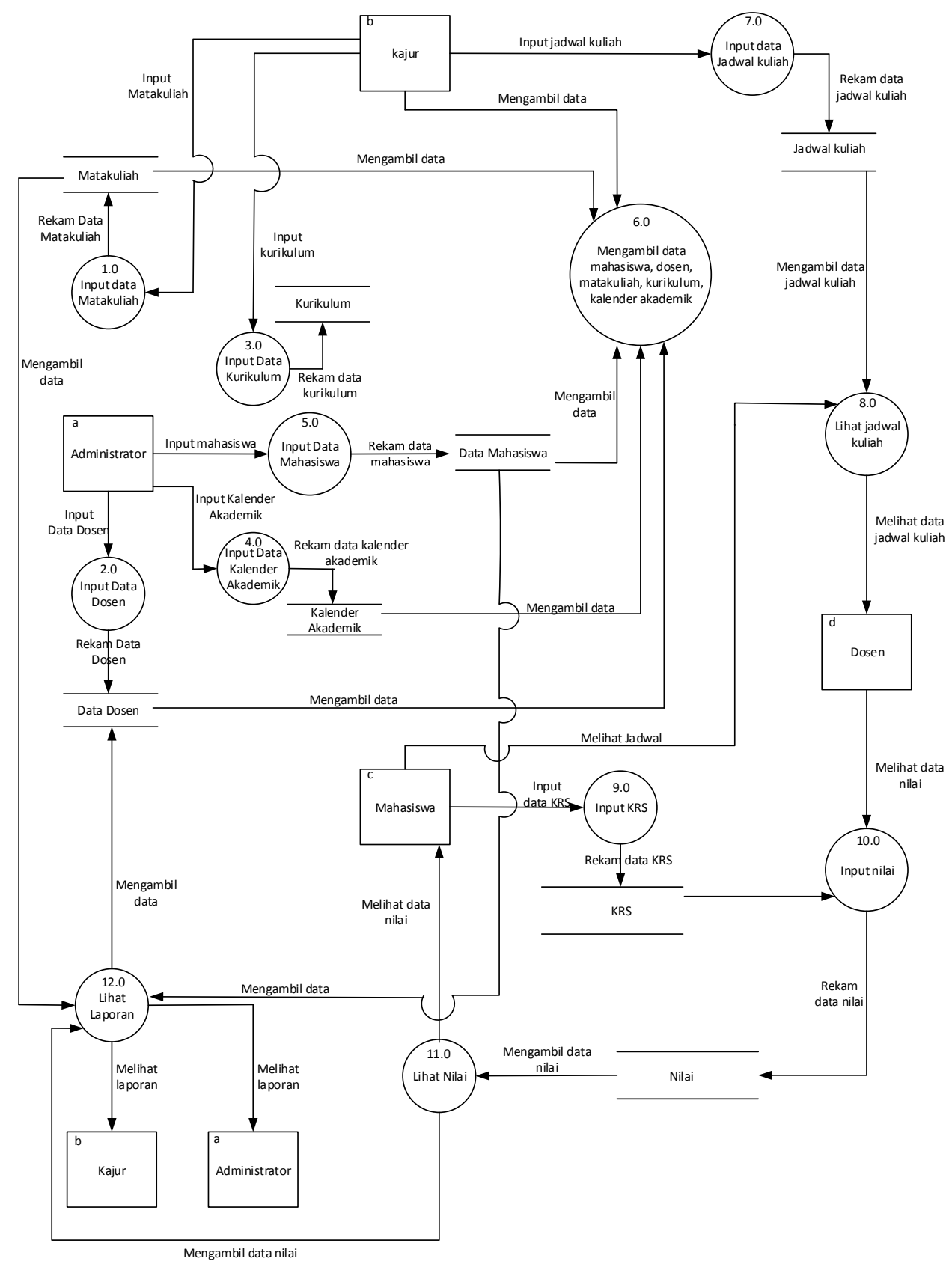

Gambar 3 : Diagram Level 1 Sistem Informasi Terpadu FMIPA

Pada DFD level 1 menggambarkan proses-proses yang ada pada sistem informasi terpadu FMIPA Universitas Tadulako. Proses - proses tersebut meliputi proses input data 
mata kuliah, input data dosen, input data kurikulum, input data kalender akademik, input data mahasiswa, input jadwal kuliah, input KRS, dan input nilai seperti dilihat pada Gambar 3.

\subsection{Rancangan Database}

1. Perancangan Database Konseptual

Perancangan secara konsep merupakan langkah pertama dalam merancang database, yaitu menentukan prosedur dan konsep yang berlaku dalam sistem database yang akan dibangun. Pada tahap ini peneliti akan menentukan prosedur dan konsep yang berlaku dalam sistem database yang akan dibangun, yaitu:
a. Prosedur Perkuliahan
b. Output yang diinginkan
c. Siapa saja yang terlibat dalam system
d. Input yang diperlukan

2. Perancangan Database Logis

Perancangan database logis merupakan tahapan untuk memetakan proses perancangan konseptual kedalam model database yang akan digunakan. Adapun tahapan-tahapannya adalah sebagai berikut.
a. Menentukan yang dibutuhkan oleh sistem
b. Menntukan attribute setiap entitas beserta kuncinya
c. Menentukan relasi antar entitas kunci tamunya
d. Menentukan Derajat Relasi
e. Normalisasi

3. Perancangan Database Fisik

Perancangan database secara fisik merupakan tahapan untuk mengimplementasikan hasil perancangan database secara logins menjadi tersimpan secara fisik pada media penyimpanan eksternal sesuai dengan DBMS yang digunakan. Dapat disimpulkan bahwa proses perancangan fisik merupakan transformasi dari perancangan logis terhadap jenis DBMS yang digunakan sehingga dapat disimpan secara fisik pada media penyimpanan.

\subsection{Hasil Penelitian}

Berdasarkan perancangan yang diusulkan maka dihasilkan sebuah Sistem Informasi Terpadu FMIPA Universitas Tadulako yang dapat diakses menggunakan web browser. Adapun hasil tampilan pada jendela browser adalah sebagai berikut :

1. Tampilan Homepage

Tampilan ini adalah halaman utama atau homepage saat pengunjung mengakses website ini. Hanya pengguna yang mempunyai hak akses saja yang dapat memasuki 
Sistem Informasi Terpadu FMIPA Universitas Tadulako ini, pengguna umum dapat melihat-lihat informasi yang ada pada halaman hompage saja.

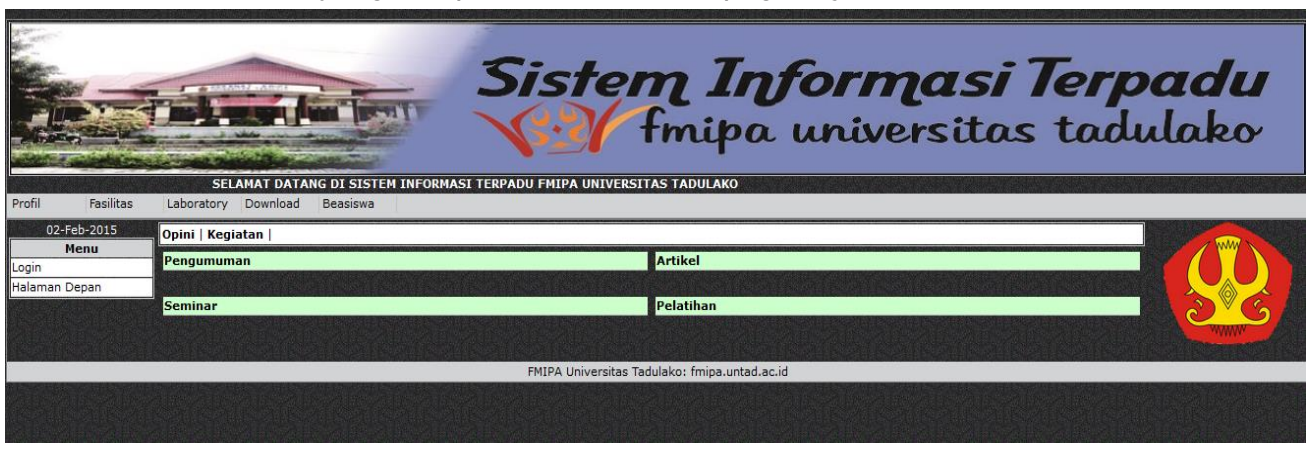

Gambar 4 : Tampilan Hompage

2. Halaman utama Mahasiswa

Pada tampilan ini mahasiswa dapat memilih menu-menu yang ada pada halaman tersebut.

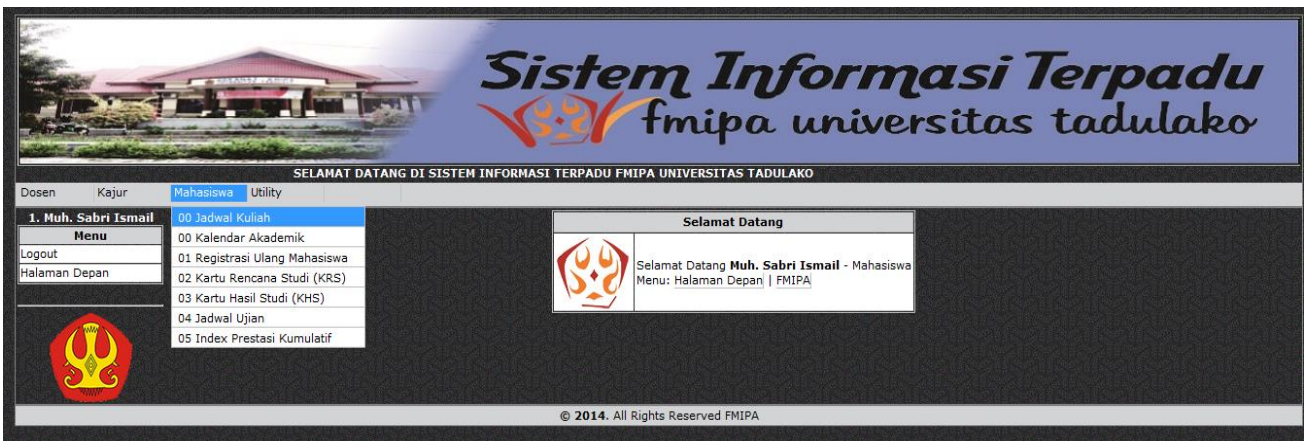

Gambar 5 : Halaman utama Mahasiswa

3. Halaman Kartu Rencana Studi (KRS) Mahasiswa

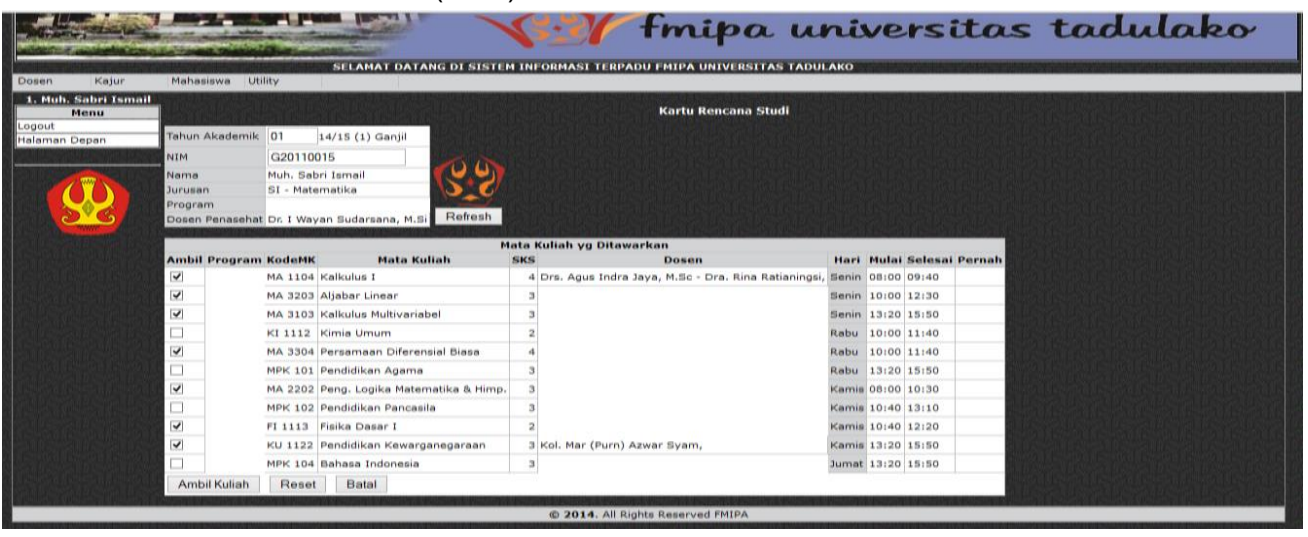

Gambar 6 : Halaman KRS Mahasiswa 
4. Halaman Penjadwalan Kuliah

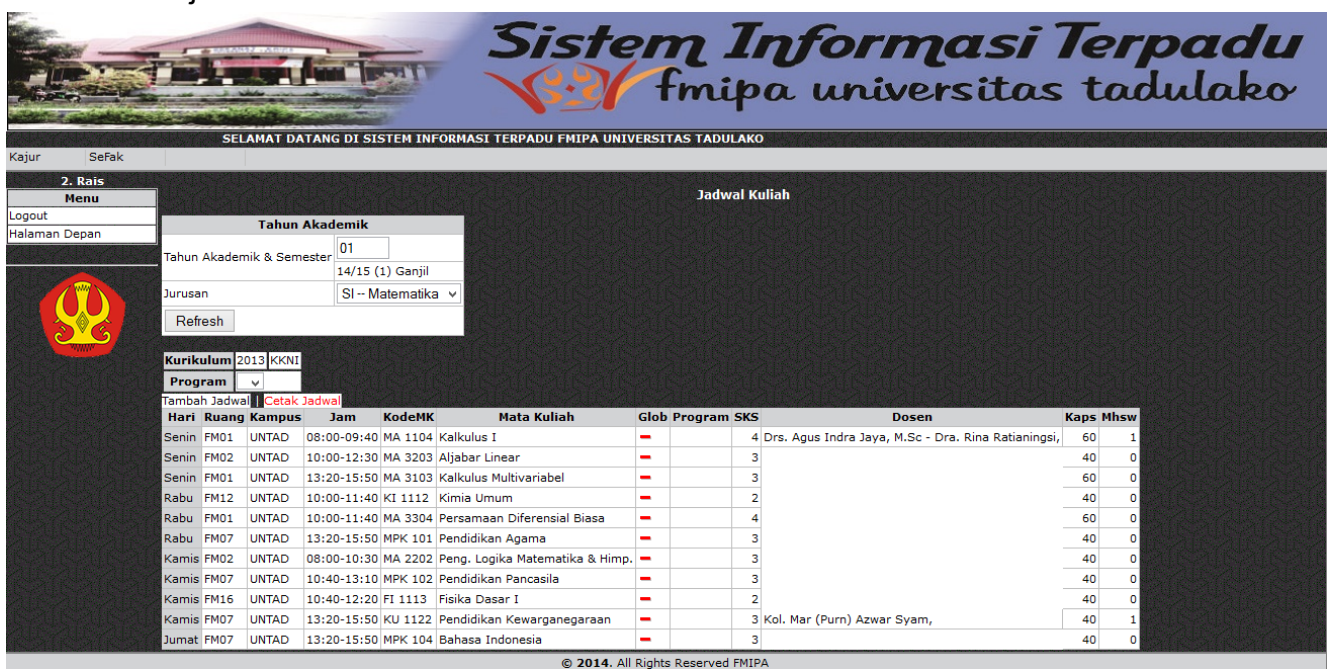

Gambar 7 : Halaman Penjadwalan Kuliah

5. Halaman Mata Kuliah

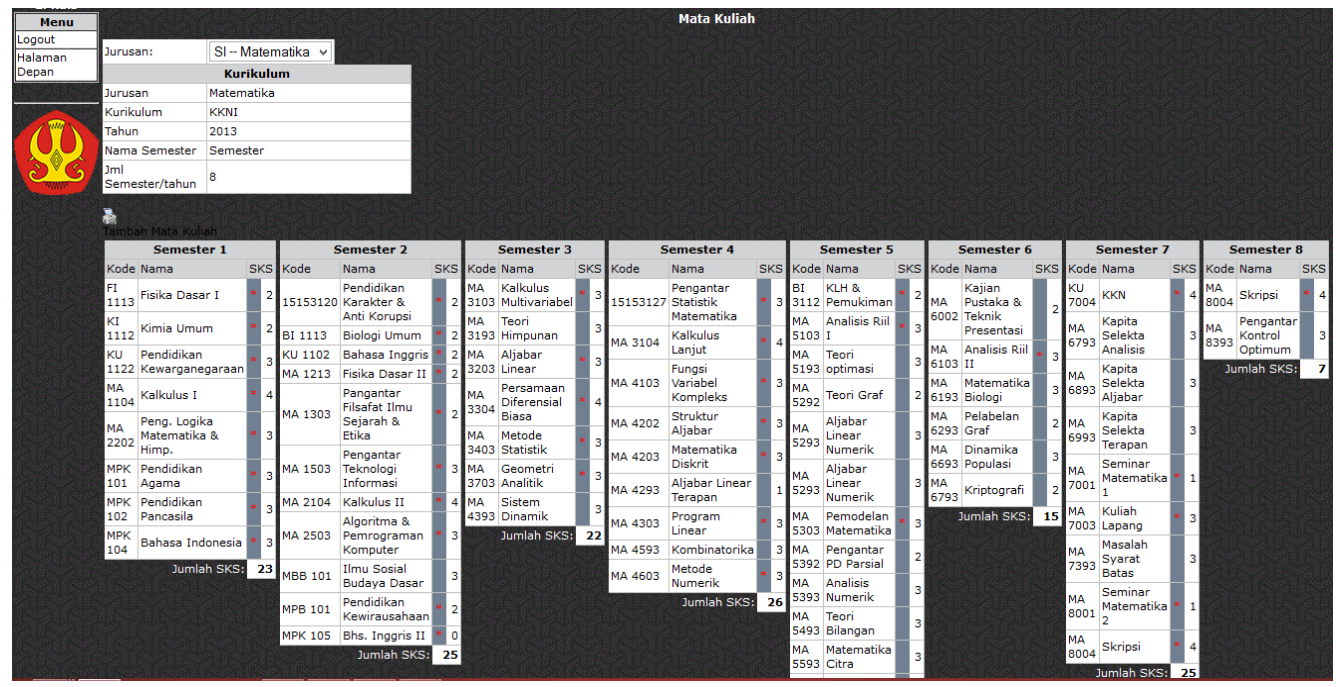

Gambar 8 : Halaman Mata Kuliah 
6.

Halaman Kalender Akademik

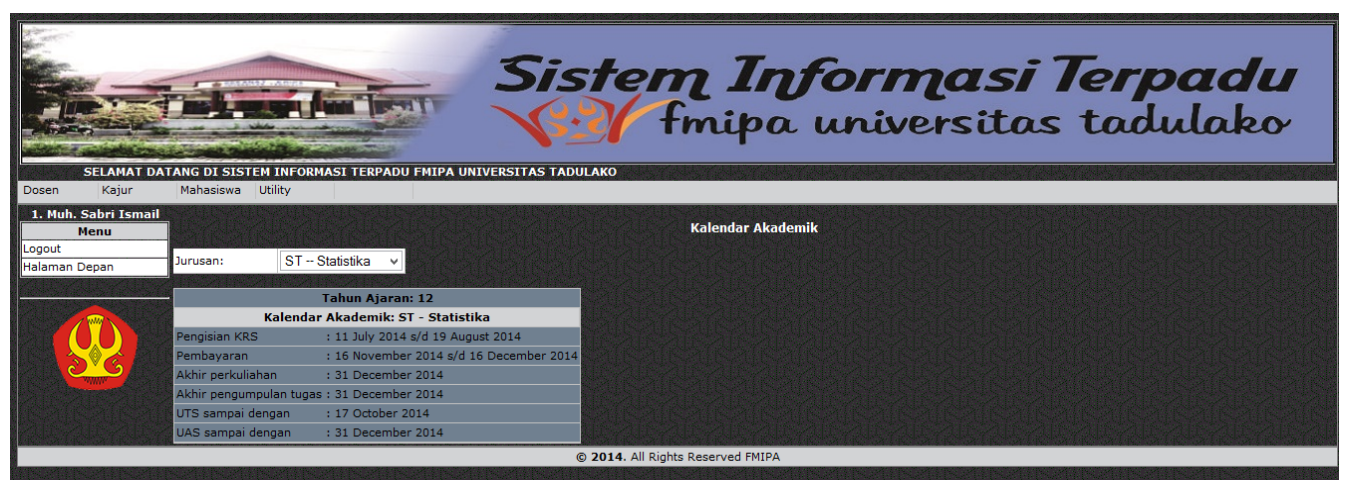

Gambar 9 : Halaman Kalender Akademik

\section{KESIMPULAN}

Dengan mengikuti beberapa tahapan peneliti akhirnya berhasil menyelesaikan sebuah "Sistem Informasi Terpadu FMIPA Universitas Tadulako" dengan menggunakan bahasa pemrograman PHP dan MySQL dan telah berhasil dirancang suatu sistem informasi kademik FMIPA yang berbasis web yang dapat beroperasi pada berbagai jenis sistem operasi dan mudah dikembangkan serta memiliki bagian berupa :

a. Pembuatan kalender akademik secara Online.

b. Pembuatan jadwal kuliah dan ujian oleh Kajur secara Online.

c. Pengisian Kartu Rencana Studi oleh Mahasiswa Secara Online.

d. Pengisian nilai oleh Dosen secara Online.

\section{DAFTAR PUSTAKA}

[1]. Anonim, 2013, Panduan Akademik FMIPA 2013-2014. UPM FMIPA Universitas Tadulako. Palu.

[2]. Anonim, 2014, Perancangan Sistem, (http://id.wikipedia.org/wiki/perancangan-sistem), diakses 13 Agustus 2014.

[3]. Anonim, 2014, Diagram Alur Data, (http://id.wikipedia.org/wiki/diagram-alur-data), diakses 19 Agustus 2014.

[4]. Budianas, Nanang., 2013, SistemAkutansi,(http://nanangbudianas.blogspot.com/2013/02/ sistem-akutansi. html), diakses 25 Juli 2014.

[5]. Hermanto, 2010, Membangun Sistem Informasi Perkuliahan Fakultas Teknik Universitas Satya Negara Indonesia Berbasis Web. Jakarta Selatan. 
[6]. Yudhistira, S., Danang, 2013, Perancangan Sistem Informasi Akademik SMP Negeri 2 Imogiri Berbasis Web, (http://repository.amikom.ac.id/ files/Publikasi_09.12.3571.pdf), diakses 26 Juli 2014. 